\title{
Historical Building Renovation as a Construction
}

\section{Project}

\author{
Daniela Dvornik Perhavec and Nataša Šuman \\ Faculty of Civil Engineering, University of Maribor, Maribor 2000, Slovenia
}

\begin{abstract}
Approaches to building renovation require high professional levels, interdisciplinary elements, team work and time to study and do research on the buildings. The process of renovating historic buildings is made up of agreements and compromises between the interests of the government, common interests, and the motives and interests of individual owners and prospective investors. Research that deals with any portion of cultural heritages always carried out very precisely, but there is still no precise knowledge of how to define a system and draw up a model that accurately represents a cultural heritage. In the existing literature on this topic, the authors have written about the different views of how to explain the construction project as a system. While many authors focus on "sub-phases" directly connected to the building of an object, the process involved in the construction phase often neglects the phases required before beginning work, which culminates in a logical sequence in the process of preparing a project. Irregularities or deficiencies which occur during the preparation process of a project often directly impact the construction itself. What the scope of this impact depends on the approach of the contractual organization, the organization of construction companies and on co-operation between the customer (or architects) and the contractors. Unlike the projects for newly built objects, the conservation projects of cultural heritage are not only more demanding because of lack of knowledge of the building materials, construction, foundation and interaction of the mentioned individual parts into a unit called a building. The authors analyzed the structural aspects of building conservation which were suggested by Beckmann and Bowles and another methodology, which was developed as part of the 5th framework program for the purpose of providing a comprehensive and interdisciplinary treatment of the revitalization of a historical city. The authors found that both methodologies do not include modern IT tools and methods. By analyzing and monitoring the restoration of historic buildings in Slovenia, specifically in the city of Maribor (including all documentation, interviews and direct views) the authors found that the project was regarded as a collection of individual projects rather than a unified whole (a system). The authors have demonstrated the consequences of structuring a historic building restoration project in a non-systemic way. This type of project can be classified as a non-sustainable renovation. In this article, at first the authors will try to clarify what types of systems and subsystems are considered in renovating historic buildings. The authors show when and why a system becomes stochastic (a probability) and in the end what would be needed to successfully re-establish it back to a determined system. By analyzing the work and reconstruction of old buildings in Maribor, the authors found that it would be necessary to give a new framework with IT tools for the preparation of a historic building restoration project.
\end{abstract}

Key words: Cultural heritages, renovation projects, general systems theory, determined systems, stochastic system.

\section{Introduction}

Before research is done, a hypothesis needs to be established that defines to what degree a project is a determined system that can be hierarchically broken down into subsystems. According to different definitions of a construction project as a system, the authors noticed that authors rarely undertake a

Corresponding author: Daniela Dvornik Perhavec, Ph.D. student, research fields: urban planning, especially the planning of buildings and renovation project. E-mail: daniela.d-perhavec@um.si. construction project as a whole system. Authors usually describe only one individual phase of a project as a system. This is because they are familiar with only a specific phase of the project. Unlike projects for newly built objects, conservation projects connected with cultural heritage are not only more complex, but are also more demanding. This is caused by a lack of knowledge about building materials, construction and the foundation as well as combining these individual parts into a unit called a building.

The conservation of cultural heritage and renovation 
of other historical buildings in clustered towns and village centers requires a whole and interdisciplinary approach, cooperation between experts and the use of modern computer-based instruments, appliances and tools with a single goal-sustainable renovation.

The sustainable approach requires a high professional level of activity, interdisciplinary team work, time to study of documentation, and do research on the buildings. The result of the reconstruction is made up of agreements and compromises between the interests of the local government and the common motives and interests of the individual owners and prospective investors. To achieve a sustainable renovation, some supportive elements are needed, such as financing, successful project management and an adequate number of qualified experts and craftsmen with special skills.

Renovation of the Naskov dvorec (mansion) was done between 2007 and 2009. The reconstruction was carried out by a trained company with years of experience in the field of renovating historic buildings. However, there occurred some errors in the implementation phase of the project. These errors were caused by actions that took place during the previous phases of the project. Half a year after the renovation of the mansion, the authors can see some visible deformation on the surface.

\section{Literature Background of Projects, Construction Projects and Systems}

Different authors on project management quote a similar classification of projects, but they are not identical. As project management deals with various projects, not just construction, a difference in classification is to be expected. The principal indentifying characteristic of a project [1] is its uniqueness. It is a step into the unknown, fraught with risk and uncertainly. Lock said [1]: "No two projects are exactly alike: Even a repeated project will differ from its predecessor in one or more commercial, administrative or physical aspects."
Loch [1] breaks down projects into four basic groups:

(1) civil engineering, construction, petrochemical, mining and quarrying projects;

(2) manufacturing projects;

(3) management projects;

(4) research projects.

Projects which are carried out only once or very rarely, in longer intervals, to achieve a strategic objective or are developed in a unique and previously unknown way are called [2] one-time projects.

Classification according to size is not known in either practice or in literature. The most common classifications differentiate among small projects, middle-size projects, large projects, big projects and multi-projects. The basic criteria [2] for classifying a project as large are: the complexity of the project, its duration and the value and risks undertaken.

To carry out a project to completion, certain financial means are necessary to cover the costs. Therefore, the authors differentiate projects according to the returns on the investments $[3,4]$ :

(1) Projects with direct economic effects-They ensure the return of the investment and after that also generate revenue which in turn brings profit and with that, a means for further development;

(2) Projects with indirect economic or other impacts-These are projects which can not ensure profit, however, they do bring about an indirect economic impact and other effects;

(3) Projects with other strategic or otherwise defined effects-e.g., construction for a specific market.

According to several authors [5-7], construction projects can be described as non-routine, non-recurring, one-time ventures, financial and technical implementation projects. They can be seen as a collection of tasks and activities, which must be completed before the end of the project. One could also say that the project is a set of a logical series of interrelated activities oriented toward the realization of set goals in a specified time frame. Each project has its 
own structure that divides the project into subprojects with partial targets.

Following the description given in the construction extension to the PMBOK Guide [6], the authors show that construction projects inherently contain a high degree of risk in their projections of cost and time. When buildings are constructed on different sites, they could be categorized as prototypical. Each project presents its own challenges in maintaining costs, time projections and control. Construction projects in the industrial sector will quite often require an intricate interface with technology licensors that can contribute to unique subcontracting arrangements, extensions to schedules and increases in capital costs. Varying authors have also stated that construction projects must address the local geography, the conditions of the project site and the relation of the project to the environment. A construction project may be phased to provide an opportunity to refine the project design at the initial phase even though there might not exist an opportunity to produce a prototype. Most important of all is that construction projects are required to have, by regulations, a team of hired specialists and construction disciplines involved in the projects. Construction projects involve many parties with varying project expectations, such as public taxpayers, regulatory agencies, governments and environmental or community groups. Other types of construction projects do not include such complexities.

General systems theory is concerned with developing a systematic framework for describing the general relationships in the natural and human-made world. The need for a general theory of systems arises out of the problem of communication among various disciplines. Although the scientific method brings a similarity between the methods of approach, the results are often difficult to communicate across disciplinary boundaries. Bertalanffy [8] used the phrase "general systems theory" around 1950. General systems theory, for him, is concerned with developing a systematic framework for describing general relationships in the natural and human-made world. Concepts and hypotheses formulated in one area seldom carry over to another, where they could lead to significant progress forward. It has operational value and reflects a new powerful view of the world, as it has synergistic properties.

As Blanchard et al. [9], a system is an assemblage or combination of functionally related elements or parts forming a unitary whole. Not every set of items, facts, methods or procedures is a system. A random group of items in a room would constitute a set with definite relationships between the items, but it would not qualify as a system because of the absence of functional relationships. The authors also indicate the critical point of a system. When designing a system, it must be explicitly defined and understood so that the system's components may be engineered to provide the desired functions, such as a desired output for each given set of inputs. A system is more than the sum of its component parts. Every system is made up of components and many components can be broken down into smaller components. The components of a system may themselves be a system and every system may be part of a larger system in the hierarchy. If two hierarchical levels are involved in a given system, the lower is called a subsystem.

System building describes man's continuing efforts to fabricate buildings faster and more economically. Construction projects as a system have been dealt with theoretically by different authors. For Dickerman [10], the systems contain three elements:

(1) clients - the system manufacturer;

(2) the builder-developer who uses systems building;

(3) the financial institution.

The authors note that the term "system" is often used without fully understanding its meaning. It is personally view on the perception of the reality. He suggests that when communicating, a special effort should be made to ensure that the context in which the term is being used is understood. For example, when 
speaking of the systems of a building, it should be assumed that only structural, mechanical and other physical elements are encompassed or that the term includes the total building process, such as market research and marketing, financing, government permits and approvals, etc.. This illustrates one distinction between "hard" and "soft" systems.

Rothenstein [11] states that a system is the complete integration of all subsystems (structural, mechanical, walls, etc.) assemblies, components and parts, into one overall system that makes full use of industrialized production, transportation and assembly. He designates "subsystems" as a term to describe all other combinations of materials or structural concepts. Within this broader concept of "systems", two general types have emerged:

(1) The "open system", which through modular coordination links diverse product components from different fabricators with other open systems;

(2) The "closed system", which is limited to elements manufactured only by the proprietary fabricator (except possibly some specialized elements such as waste disposal, heating, lighting, etc.).

Loncaric [5] demonstrated that the execution of a construction project could be defined as dynamic, complex, open, organizational or stochastic.

Kast et al. [7] see a system as a unique whole created by two or more independent parts, limited by the surrounding (supra) system.

Furthermore, Zaja [12] defines a system as a coherent whole, while each consisting part of the whole is directed to fulfilling a common goal.
Meredith [13] describes a system as a set of elements connected with a certain interaction or dependency, which react together to the initiatives and demands from the environment and which fulfill a certain purpose or perform a certain function.

The authors have too many interconnections and many authors focused to one part of the system. Can people find a system which would describe a restoration project of a cultural heritage building?

A lot has been written about the system theories so far. Therefore, the authors will not look broadly neither at the types of systems nor at the system theories in this article. The authors will mention only the basic definitions and those pertaining to the system descriptions of construction projects.

By analyzing many studies from different authors show, how difficult find a system and set up a model which would describe a restoration project of a cultural heritage building, despite in-depth research of any segments of cultural heritage.

In Table 1, it can be concluded that there is no unified way of describing construction projects and that individuals, using the word "system", have been describing separate phases of the project.

Most construction projects can be broken down into five phases, although there are sometimes four. These phases [6] are:

(1) concept;

(2) planning (and development) or preliminary design phase;

(3) detail design phase;

(4) construction phase;

Table 1 The construction project as a system.

\begin{tabular}{|c|c|c|c|c|}
\hline \multirow{2}{*}{ Projects } & \multicolumn{3}{|c|}{ Construction phase } & \multirow{2}{*}{$\begin{array}{l}\text { Operational phase } \\
\text { Product use, support, phase-out and disposal }\end{array}$} \\
\hline & Preliminary design & Detail design & Construction & \\
\hline Dickerman & \multirow[t]{2}{*}{ Soft } & & \multicolumn{2}{|l|}{ Hard } \\
\hline Loncaric & & & \multicolumn{2}{|c|}{ D, C, O, ORG, S } \\
\hline Kast & \multicolumn{4}{|c|}{ The whole of two or more independent parts, limited by the surrounding (supra) system } \\
\hline Meredith & \multicolumn{4}{|c|}{ A set of elements which react together with the initiatives and demands of the environment } \\
\hline Rothenstein & \multicolumn{4}{|c|}{ Full integration of all subsystems—open and closed systems } \\
\hline Rosenzweig & \multicolumn{4}{|c|}{ The whole of two or more independent parts, limited by the surrounding (supra) system } \\
\hline Zaja & \multicolumn{4}{|c|}{ A coherent whole directed toward fulfilling a common goal } \\
\hline
\end{tabular}

$\mathrm{C}$ = complex; $\mathrm{D}$ = dynamic; $\mathrm{O}$ = open; ORG = organizational; $\mathrm{S}$ = stochastic. 
(5) start up and turnover.

The construction phase can be divided into works related to the preparation of construction and works directly with the building of the object itself.

Processes overlap throughout the entire project or project phase. The processes are described by the following terms [6]:

(1) inputs (planning outputs, historical information, organizational policies, constraints, assumptions, etc.);

(2) tools and techniques (project planning methodology, the skills and knowledge of the subcontractors, project management, information systems, etc.);

(3) outputs (project plan, documents, supporting detail, etc.).

Systems are composed of components (elements or parts of a system), attributes (properties as characteristics, configuration, qualities, powers, etc.) and the relationships among these elements.

A system can be mathematical expressed as:

$S=\{E, a, r\}$

$S=$ system, $E=$ elements (components), $a=$ attribute (properties) and $r=$ the relationship between the elements.

Materials, energy and/or information that pass through the boundaries of a system are inputs, while outputs are materials, energy and/or information that pass from the system to the environment. That which enters the system in one form and leaves the system in another form is usually called throughput [14]. The state of a system is the situation (condition and location) at a point in time of the system, or of a system component with regard to its attributes and relationships. Components and attributes are important, but only if a whole system is achieved through the functional relationships linking them $[14,15]$.

Fig. 1 shows the relationship between the inputs and outputs of a system.

The defined relationship between the inputs and outputs of a system is the same as the description of the processes of the system as they relate to the construction project. This is the connecting point between the system and the project.

\section{From Preliminary Design to the Construction Phase}

Each construction project is unique within the classic scopes of minimum cost at highest quality [16]. The newest approaches of construction management add to this classification: effectiveness of implementation and customer expectation [17, 18]. Regardless of the type of object being built, the project must have the following qualities:

(1) technically correct construction;

(2) time efficient construction;

(3) economical construction.

If a project has well defined objectives based on strategies that will ensure high quality construction work, it can not be considered as a determined system.

Due to the properties and features of various systems, such as analysis, synthesis and decomposition, the decision of whether to treat phases of a project as either a part of the system or a subsystem lies with the system designer. Loncaric [5] precisely defines the execution phase of a construction project as dynamic, complex, open, organizational, stochastic, systematic or sub-systematic.

The conception phase has a great effect on the construction phase, especially in conservation projects that preserve a cultural heritage. The building contractor is able to do their job well and professionally only when the previous phases are well done. If the conception phase neglects necessary activities, the contractor will have to deal with them later. Each change in the project represents a disruption, which has

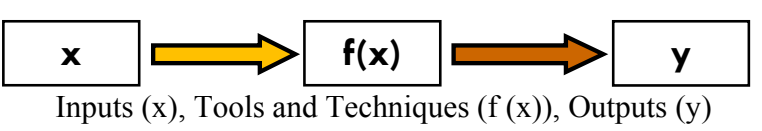

Fig. 1 Relationship between the inputs and outputs of a system. 
to be dealt with quickly and with as little cost as possible. The costs and efforts involved in the implementation of the project are as follows: lower in the conception and design phases and considerably higher in the construction phase.

Fig. 2 shows the main points that investors must pay special attention to if they want to minimize disruptions in the construction phase.

\section{From a Determined System to a Stochastic System}

When there is no detailed analysis of an existing situation, restoration projects that involve historical buildings can be described using probability systems. These can be divided into probabilistic and stochastic systems. The stochastic system can sometimes be used to denote a system with an indefinite time element. There are generally two reasons why a system behaves stochastically:

(1) A determined system is subjected to external influences that are stochastic in character;

(2) The internal mechanisms of the system change due to unknown reasons, although they are assumed to be stochastic.

In these cases, the authors are only referring to changes that take place within construction projects that involve the restoration of historical buildings.

The authors can say that Fig. 3 is a determined system (D) subjected to the effects of a stochastic nature (unknown external effects). Because of this, the system changes from a determined to a non-determined system in the conception phase. This, however, later leads to changes in the execution phase, which can affect the system to such extent that the authors can then refer to it as a stochastic system.

In every case of stochastic behavior uncertainty can appear which generally means that there is no previous knowledge needed to complete the task. There can be several types of uncertainty. The system can include decisive tasks, which are not known in advance. The system's characteristics may not change over a given period of time, while in other situations they change considerably or in an unknown way. In such cases various uncertainties regarding the state of the system are likely to appear, such as the goal of a system, the criteria used and the limitations of the resources. Uncertainties deriving from external interference or impact from the environmental all have an effect on the system. The usual way of presenting uncertainties is by the use of stochastic models. When the authors come upon various types of uncertainties while managing systems, it is possible to rely on learning from experience

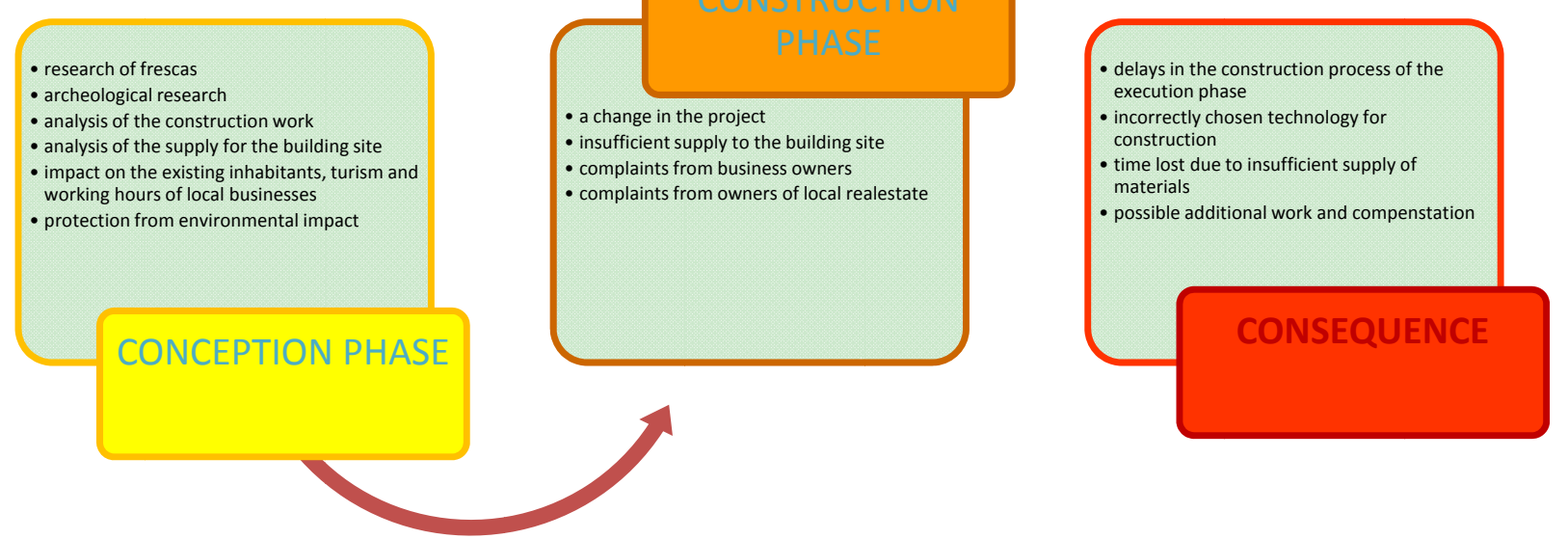

Fig. 2 Impact of deficiencies in the conception phase and effects on the construction phase for the restoration of historic buildings. 


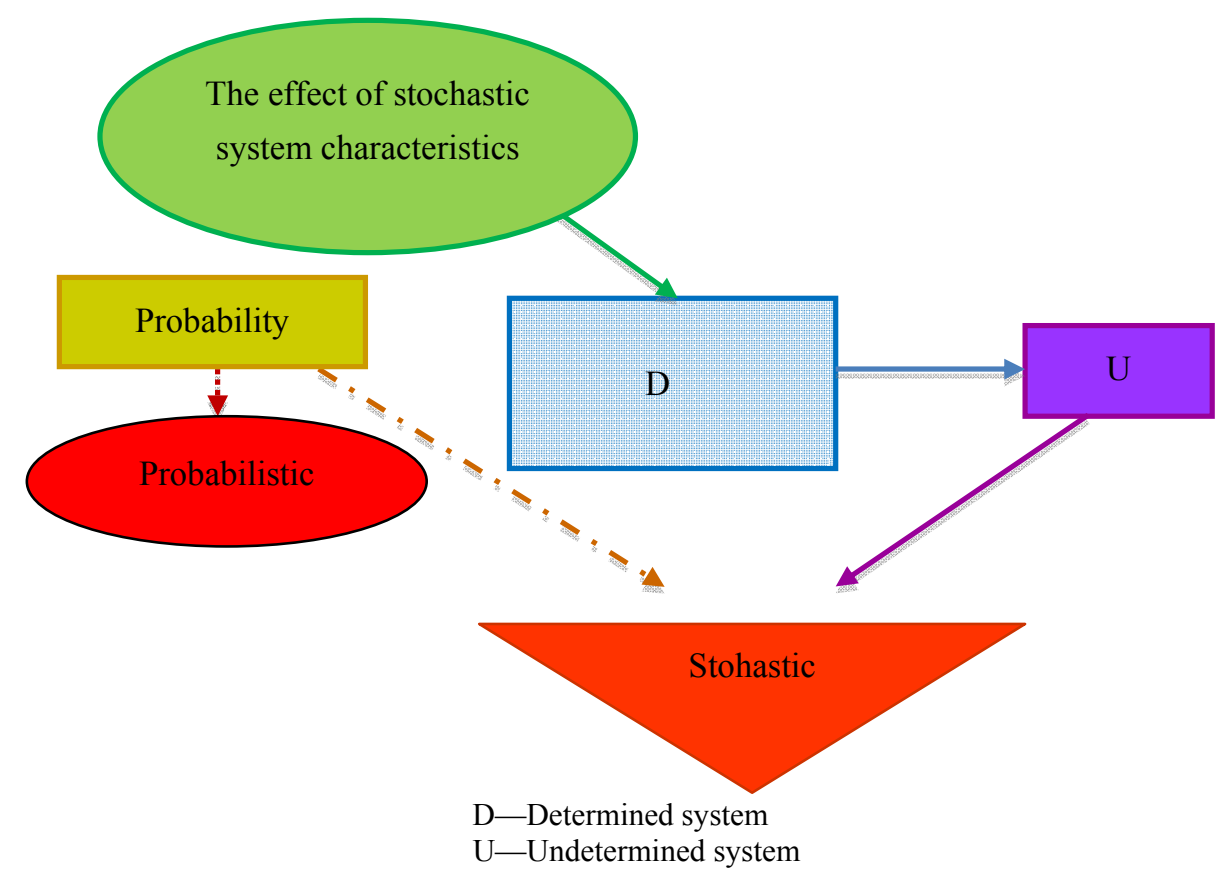

Fig. 3 The effect of stochastic characteristics on a determined system.

in order to solve problems. In this way, knowledge is broadened and information can be added to the unknown aspects of a system. These processes are called adaptive processes and are typical of technical and economic systems. Forecasting, game theory and other theories present a new platform in the treatment of uncertainties. In restoration projects that deal with historical objects, stochastic systems can be formed when not enough resources or time have been dedicated to the research of the building.

Table 2 shows both determined and stochastic systems of a project [19].

Discovering historically valuable architecture or deviating from the project during renovation makes it risky for the investors and disorganizes the project from the perspective of the management team. Information technology has contributed to making such projects less risky. The question is whether the available knowledge, technology, modern instruments, information systems and various technologies used in the identification and documentation of existing facilities are sufficient to eliminate these risks. Information about buildings (material, construction, painting, walls and archeology) which has existed for over 100 years, demands the systematic treatment of the building at the time of its renovation. On the other hand, a determined system is established between the customer or investor and the contractor, which is reflected in their contractual relationship. As in the reconstruction projects of historical buildings the determined system thus collapses and it changes into a stochastic one, there is a great degree of risk in the execution of the project involved both for the customer or investor as well as for the contractor.

Methods of obtaining data of the existing building may be different. It is important to capture the entire object and all of the contents that can lead to subsequent disturbances in the construction phase. The methodology of analyzing facilities, with an emphasis on the analysis of construction was first given in 1980, and later in 1996 [20]. Backmann et al. [21] believe the process of analyzing historical building facilities covers the research of documentation, measurements of the objects, geodetic and other recordings, structural analysis, material analysis and other analyzes.

The data obtained from the research serves as an input to produce documentation and successful implementation of projects. Input data can be obtained 
Table 2 Relationship between the phases of the project and its systems.

\begin{tabular}{lll}
\hline Phases of a project & Conditions or requirements for a specific system & Type of subsystem \\
\hline $\begin{array}{l}\text { Conceptual/preliminary } \\
\text { design }\end{array}$ & $\begin{array}{l}\text { Detailed analysis of the cultural heritage, including all scientific disciplines } \\
\text { Detailed analysis of the cultural heritage is not done }\end{array}$ & $\begin{array}{l}\text { DET } \\
\text { STOH }\end{array}$ \\
\hline $\begin{array}{l}\text { Detail design and } \\
\text { development }\end{array}$ & $\begin{array}{l}\text { Previously a determined system } \\
\text { Previously a stochastic or determined system, system accompanied by poor analysis of } \\
\text { the cultural heritage }\end{array}$ & DET \\
\hline \multirow{2}{*}{$\begin{array}{l}\text { STOH } \\
\text { Previously a determined system } \\
\text { Previously a stochastic or determined system with irregularities in the } \\
\text { construction/execution of the project or other discrepancies (treatment site) [19] }\end{array}$} & DET \\
\hline
\end{tabular}

$\mathrm{DET}=$ determined system, $\mathrm{STOH}=$ stochastic system.

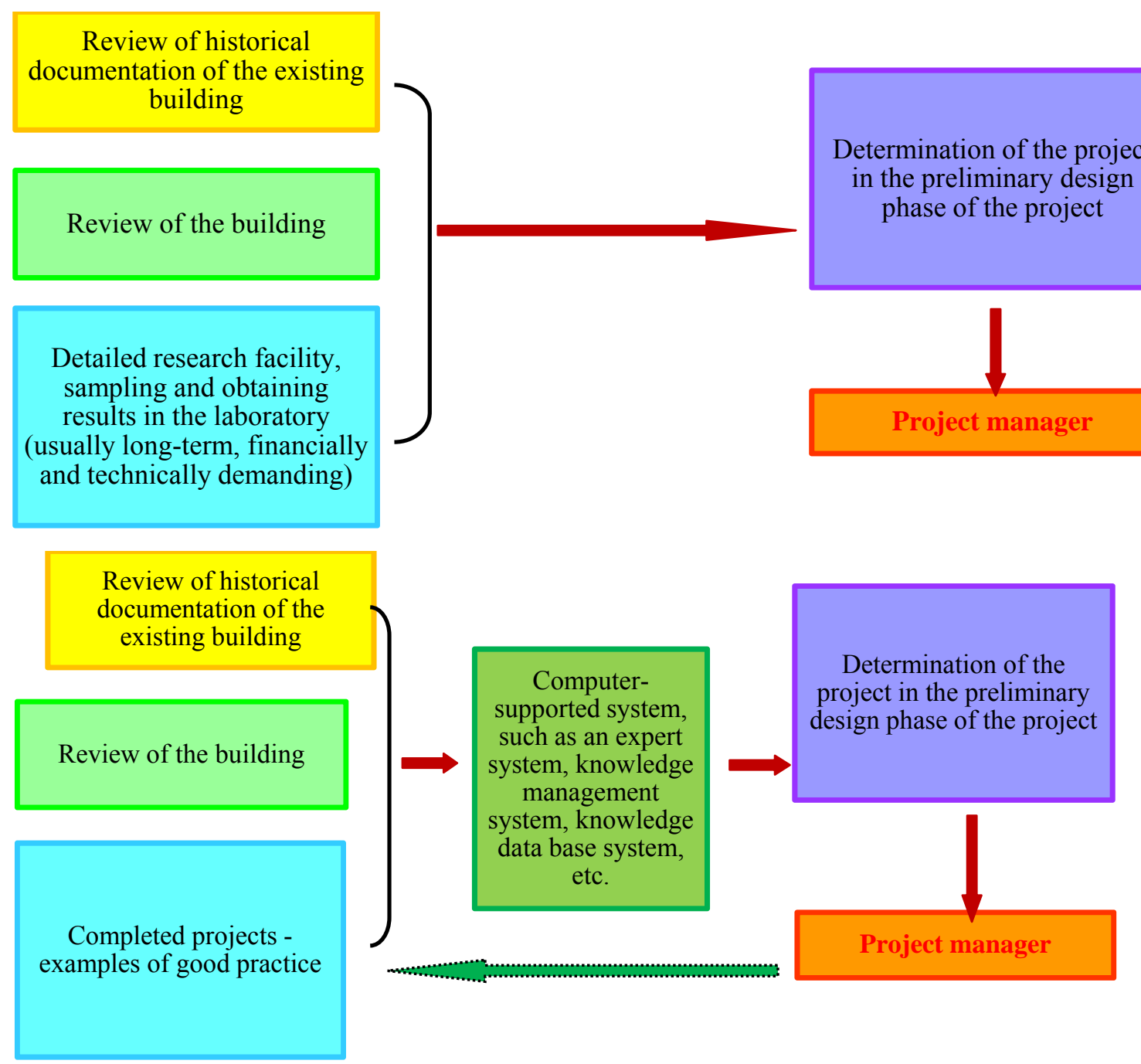

Fig. 4 How the input data was obtained.

in several ways (Fig. 4).

With the help of hybrid methods and the recorded data in the BIM (building information modeling) Standards, there is now a basis for further work for designers and other participants. The BIM standards allow further implementation of the monitoring facilities [22].

\section{Discussions}

In the past, knowledge of systems was more 
spontaneous. The systems theory did not exist, but there existed the knowledge and systematical thinking involved in construction projects [23]. The authors can not accurately imagine Egyptian pyramids and cities without knowledge about systems.

In 1979 , Bertalanffy [8, 24, 25] pointed out that a complex system is more than the sum of its individual parts. Since a system can be thought of as a product of human thought, one must acknowledge the effect that this process would have on a construction system. Consequently, it has an effect on the perception of the reality perceived through the system. In other words, the system is not the reality itself but rather its author's perception of the reality, or at least part of it. It can be concluded that a significant proportion of the complexity of a system comes from its perception, not just from its individual parts and by the way these parts are linked together.

The systems theory was always meant to be an integrative tool for all sciences, aiming for a dialogue between scientific disciplines. However, construction projects that deal with the renovation of historical buildings combine a wide range of different scientific disciplines [24, 26].

The authors can use the definition of determined, undetermined and stochastic projects and compare them, in a parallel way, to other systems with the same definition. All authors $[5,10]$ etc. agree on the construction phase. The construction of a project is treated as a system affected by the previous phases of the project and other subsystems.

If the construction phase in a historical restoration project wants to be treated as a determined system, one of the following criteria needs to be fulfilled:

(1) Each subsystem of the construction project must be decelerated determined;

(2) In a stochastic subsystem, it must be introduced systems, which ensures determined project completion despite the stochastic behavior of the subsystem.

Changing the system from a less determined to a more determined system is possible by means of the mechanisms of the control systems. Further research is needed in order to find out which control systems are required to change a particular subsystem. Further research is needed in the direction of researching information systems, knowledge management systems, expert systems and data base systems. Information about buildings (material, construction, painting, walls, archeology) which has existed for over 100 years, demands the systematic treatment of the building at the time of its renovation. In the case of the "Naskov mansion" in Maribor, it has been shown that the thickness of the plaster was three or more inches deep (in multiple layers) and that original relief paintings were located on the second layer of plaster (in the direction of the wall towards the outside). They were discovered accidentally, despite the fact that they used the regular testing methods. This has led to congestion at the construction site (an unexpected increase of work) and additional costs. The authors would like to find a way to use their research results so that they can be of more use for future research and in so doing, also find a way to change stochastic systems.

\section{Conclusions}

In this article, the authors have focused on the determined, undetermined, probability and stochastic systems. They have come to the conclusion that there is no uniform definition which can describe a construction project as a system.

Construction projects mostly include technical expertise (architecture, surveying, structural and civil engineering, mechanical engineering, electro technological engineering, etc.). On the other hand, historical restoration projects fall roughly under the topic of humanities and include use of both the social and natural sciences. Here the authors have to deal with other factors which can affect and change the determined systems. The construction phase of historical restoration projects is basically similar to the construction phase of other construction projects, 
except that in restoring historical buildings a larger number of experts and artisans need to be involved. Generally, the authors can describe construction projects as determined systems. However, the same can not be stated with certainty concerning historical restoration projects. They can conclude that other factors (previous phases) affect the latter and thus reclassify them from determined systems into stochastic systems.

Due to the interaction of the social and historical sciences in restoring historical buildings, the authors have a complex problem to deal with. In the past, individual system characteristics were poorly investigated. Understanding the system alone is not sufficient anymore. Therefore, the relationship between the individual system and the goal of construction project must be known as well.

To achieve a sustainable restoration project, certain supportive elements are needed, such as financing, successful project management, adequate number of qualified experts and craftsmen with special skills. A comprehensive treatment of each building would involve modern information systems and technology and an appropriate presentation and commitment to build a database of information related to the entire local cultural heritage. It is necessary to apply the knowledge that is already available, such as archival data, archival projects, basic and specialized literature relating to existing facilities [27], other studies made by institutions and in scientific and professional journals and successful practice examples [28, 29]. It is then necessary to find a common ground of previously researched data, laws and rules for the purpose of connecting them and using them in a new project with the goal of preparing an effective project preparation and sustainable reconstruction of a historical building. On the other hand, a determined system is established between the customer or investor and the contractor, which is reflected in their contractual relationship (for example FIDIC (Federation Internationale des Ingeniuers-Conseils)
[30]. And in the example of restoring historical buildings the determined system collapses and changes into a stochastic one. There is a great degree of risk in the construction phase of a project that involves and influences both the customer or investor and the contractor.

\section{References}

[1] D. Lock, Project Management, 9th ed., Gower Publishing Ltd., Aldershot, 2007, pp. 1-8.

[2] A. Hauc, Projektni Management, GV Zalozba, Ljubljana, 2007, pp. 77-114. (in Slovene)

[3] D.D. Rypkema, Feasibility Assessment Manual for Reusing Historic Buildings, National Trust for Historic Preservation, Washington, DC, USA, 2007, pp. 2-8.

[4] D.D. Rypkema, The Economics of Historic Preservation, 4th ed., National Trust for Historic Preservation, Washington, DC, USA, 2008, pp. 89-99.

[5] R. Lončarić, Organization of Performance of Construction Projects, Croation Society of Civil Engineers, Zagreb, 1995, pp. 9-35. (in Croation)

[6] Project Management Institute, Inc., Construction Extension to the PMBOK Guide, 2nd ed., Project Management Institute, USA, 2007, pp. 5-12.

[7] F.E. Kast, J.E. Rosenzweig, Organization and Management, A System Approach 2002, McGraw-Hill, New York, 2002.

[8] L. Bertalanffy, General System Theory, Foundations, Development, Applications, George Braziller, New York, 1968.

[9] B.S. Blanchard, W.J. Fabrycky, Systems Engineering and Analysis, Pearson Education, Inc., New York, USA, NY, 1981, 1990, 1998, 2006, 2011, pp. 17-18.

[10] J.M. Dickerman, Facts and fictions about systems building, The Appraisal Journal 41 (4) (1973) 548-557.

[11] G.A. Rothenstein, Industrialized Housing, Joint Economic Committee Congress of the United States, Apr. 1969, p. 182.

[12] M. Zaja, Cybernetics and General Systems Theory, Civil Engineering Institute, Zagreb, 1988. (in Croatian)

[13] D.D. Meredith, Design and Planning of Engineering Systems, Prentice Hall, Englewood Cliffs, USA, 1973.

[14] U. Kordeš, From Truth to Faith, Studija Humanitatis, Ljubljana, 2004, pp. 32-58.

[15] M. Mulej, V. Potočan, Complexity theory belongs to more systems theory streams, Journal of Management, Informatics and Human Resources 39 (1) (2006) 96-97.

[16] A Guide to the Project Management Body of Knowledge, 3rd ed., Project Management Institute, 2005.

[17] D. Haughey, An Introduction to Project Management 
[Online], 2009, http://www.projectsmart.co.uk/ introduction-to-project-management.html (accessed Jan. 5, 2012).

[18] J.A. Fapohunda, S.S. Omoniyi, Enhancement of site managers efficiency towards accomplishments of project objectives, Organization, Technology and Management in Construction, an International Journal 2 (2) (2011) 308-316.

[19] D.D. Perhavec, Conservation of cultural heritage-Disorders, deficiencies and building project, in: 3rd international conference GNP 2010 "Civil Engineering-Science and Practice", Faculty of Civil Engineering University of Montenegro, Žabljak, 2010, pp. 1245-1250.

[20] Appraisal of Existing Structures, Institution of Structural Engineers, 1996.

[21] P. Beckmamm, R. Bowles, Structural Aspects of Building Conservation, Elsevier, The Netherlands, 2004, pp. 24-323.

[22] D. Rebolj, N.Č. Babič, A. Magdič, P. Podbreznik, M. Pšunder, Automated construction activity monitoring system, Elsevier 22 (4) (2008) 493-503.

[23] H. Galal, G. Edeen, System architecting: The very idea, Logistics and Information Management 16 (2) (2003) 101-106.

[24] M. Drack, G. Schwarz, Recent Developments in General System Theory, Systems Research and Behavioral Science,
John Wiley \& Sons, Ltd., 2010.

[25] D.D. Pouvreau, On the history of Ludwig von Bertalanffy's "General Systemology", and on its relationship to cybernetics-Part I: Elements on the origins and genesis of Ludwig von Bertalanffy's "General Systemology", International Journal of General Systems 36 (3) (2007) 281-337.

[26] D. Manfred, W. Apfalter, Is Paul a Weiss and Ludwig von Bertalanffy's system thinking still valid today?, Systems Research and Behavioral Science 24 (5) (2007) 537-546.

[27] C. Beall, Masonry Design and Detailling, McGraw-Hill, New York, 1997.

[28] P. Dorninger, W. Kippes, J. Jansa, Technical push on 3D data standards for cultural heritage management, CORP 2005 and Geomultimedia 05, in: 10th International Conference on Information and Communication Technologies (ICT) in Urban Planning and Spatial Development and Impacts of ICT on Physical Space, Wien, 2005, pp. 281-287.

[29] Z. Akdemir, G. Sener, The Assessment of Kirkgoz Bridge in the Contex of Sustainable, Cultural and Architectural Heritage, The Sustainable World, The Wessex Institute of Technology (WIT), Sauthampton, 2010, pp. 117-129.

[30] Construction, Construction, Federation Internationale des Ingeniuers-Conseils, Lausanne, Switzerland, 1999, pp. 38-134. 